\title{
N-Doped Carbon Aerogels Obtained from APMP Fiber Aerogels Saturated with Rhodamine Dye and Their Application as Supercapacitor Electrodes
}

\author{
Lei E, Wei Li *(D), Jiaming Sun, Zhenwei Wu and Shouxin Liu* \\ Key laboratory of Bio-Based Material Science and Technology, Ministry of Education, Northeast Forestry \\ University, Harbin 150040, China; eleinefu@163.com (L.E); sjmnlxx@126.com (J.S.); wzwww0413@163.com (Z.W.) \\ * Correspondence: liwei19820927@126.com (W.L.); liushouxin@126.com (S.L.); \\ Tel./Fax: +86-451-82191204 (W.L.); +86-451-82192789 (S.L.)
}

Received: 10 January 2019; Accepted: 10 February 2019; Published: 13 February 2019

\begin{abstract}
We developed an efficient and environmentally friendly strategy for synthesizing an $\mathrm{N}$-doped carbon aerogel by the carbonization of an alkaline peroxide mechanical pulp (APMP) fiber aerogel saturated with rhodamine B (RB) dyes. The APMP aerogel was prepared via cellulose extraction, sol-gel, and freeze drying. The resulting aerogel had a high adsorption capacity $\left(250 \mathrm{mg} \mathrm{g}^{-1}\right)$ and a fast adsorption rate (within $30 \mathrm{~s}$ ) towards RB dyes. The saturated aerogel was used as a starting material for further carbonization to prepare $\mathrm{N}$-doped carbon aerogels. SEM studies showed that the 3D network structure of the APMP aerogels was well preserved after RB adsorption and carbonization. The prepared carbon aerogel exhibited a graphitized structure, and $\mathrm{N}(2.15 \%)$ was doped at pyridinic $\mathrm{N}$ and pyrrolic $\mathrm{N}$ sites in the 3D carbon network. The specific capacitance of the $\mathrm{N}$-doped carbon aerogel reached $185 \mathrm{~F} \mathrm{~g}^{-1}$ at a current density of $1 \mathrm{~A} \mathrm{~g}^{-1}$, which is higher than carbon aerogels $\left(155 \mathrm{~F} \mathrm{~g}^{-1}\right)$.
\end{abstract}

Keywords: aerogel; carbon aerogel; N-doped; rhodamine B; supercapacitors

\section{Introduction}

Owing to the global energy crisis, the demand for higher energy and power storage equipment is increasing [1-3]. Supercapacitors, an electrochemical capacitor, have a long cycle life, high-power density, high charge/discharge rate and good safety [4]. These devices show great potential for efficient energy storage [5] and for use in electric vehicles, batteries, and wind power. According to the charge storage mechanism of the electrode, supercapacitors can be classified as either electric double-layer capacitors (EDLCs) or pseudocapacitors. EDLCs exhibit a non-faradic reaction as charges accumulate at the electrolyte interface and electrode, whereas pseudocapacitors show faradic redox reactions [6,7]. The electrode is one of the most important parts of a supercapacitor, and it is important for an ideal electrode material to have a suitable porous structure and an ion-contactable specific surface area [8]. Furthermore, there is also a trend towards using renewable biomass for electrodes [9,10]. In particular, recent findings have revealed that the engineering of carbon materials by doping nitrogen $(\mathrm{N})$ is an efficient method of improving specific capacitance performance because the nitrogen-containing functional group can undergo a Faraday reaction and improve the wettability of the pore walls, and nitrogen doping could increase the conductivity of carbon material [11-14].

There are two main methods for synthesizing nitrogen-doped carbon materials, in-situ doping and post-treatment. In-situ doping approaches include chemical vapor deposition, arc-discharge methods, and the treatment of porous carbon materials with nitrogenous compounds, for example, amines [15], ammonia [16], bone char [17], or polymelamine [18]. Post-treatments include carbonization with 
nitrogen-rich compounds $[17,19]$ and in a nitrogen-donor atmosphere [20]. However, the expensive and complex instruments and toxic precursors may limit their practical application. Thus, the selection of appropriate $\mathrm{N}$ sources, the development of environmentally friendly and simple methods to prepare nitrogen-doped carbon aerogels are highly desirable but challenging targets.

Aerogels are solid materials obtained by replacing a liquid or gel phase with a gas while leaving the solid network of the gel intact [21-25]. As a family of 3D network porous materials, aerogels can be produced from biomass such as cotton [26-28], bagasse [29], bamboo [30], and bacterial cellulose [31]. Due to their large porosity, low density, high specific surface area, and wettability [32], aerogels have been extensively used in gas sensors [33], catalyst supports [34], and adsorbents [35]. Carbon aerogels, obtained by aerogel carbonization, exhibit both the high specific surface area and porosity of aerogels and the electrical conductivity and high chemical stability of the carbon materials, making them an ideal electrode material for supercapacitors [36-39]. However, the electrochemical performance of unmodified carbon aerogels has been unsatisfactory to date [40]. Rhodamine B (RB), a toxic dye, is extensively used in daily life and industrial manufacture and represents a serious and difficult-to-remedy environmental threat. The chemical structure of RB organic dyes contains a large number of nitrogen atoms [41], making RB a suitable candidate precursor for preparing N-doped carbon materials. Furthermore, taking full advantage of N-rich waste based on RB organic dyes will enable effective resource recycling.

In previous papers, cellulose-based aerogels have been shown to absorb a range of organic dyes because they have good wettability and many functional groups on their surface [42]. We removed RB using an alkaline peroxide mechanical pulp (APMP) fiber aerogel as the sorbent and used the aerogel saturated with RB dye to obtained N-doped carbon aerogels for supercapacitors. Herein, $\mathrm{RB}$ adsorbed onto the APMP aerogel was used as a nitrogen source, and $\mathrm{N}$-doped carbon aerogels were successfully obtained after carbonization of the aerogels saturated with RB dye. We also investigated their electrochemical properties as electrodes of supercapacitors.

\section{Materials and Methods}

\subsection{Materials}

The alkaline peroxide mechanical pulp (APMP) used was from Mudanjiang Hengfeng Paper Co. Ltd., Mudanjiang, China. Rhodamine B and sodium chlorite were obtained from Kermel LLC (Tianjin, China). Glacial acetic acid, sodium hydroxide, and urea were all obtained from Guangfu LLC (Tianjin, China).

\subsection{Preparation of APMP Fiber Aerogel}

The purification of APMP fiber from APMP waste was conducted by alkaline hydrolysis according to reported methods [34]. The dried APMP powder was treated with a sodium chlorite and glacial acetic acid mixture to remove hemicellulose and lignin. The mixture was maintained in a $4 \%$ sodium hydroxide solution at $80^{\circ} \mathrm{C}$ for $4 \mathrm{~h}$ to remove residual hemicellulose and lignin. The APMP fibers were washed repeatedly with deionized water until neutral. A $2 \mathrm{~g}$ portion of the prepared APMP fibers was dispersed into a precooled $\mathrm{NaOH} / \mathrm{urea} / \mathrm{H}_{2} \mathrm{O}(8: 12: 81 w / w)$ solvent system and stirred vigorously for $6 \mathrm{~h}$ to form a cellulose suspension $\left(4^{\circ} \mathrm{C}\right)$. The cellulose suspension was kept for $15 \mathrm{~h}$ to form a cellulose hydrogel $\left(50^{\circ} \mathrm{C}\right)$. The hydrogel was regenerated in water and washed with deionized water until neutral, then freeze-dried for $50 \mathrm{~h}$ to obtain the APMP fiber aerogels.

\subsection{Adsorption Performance of APMP Aerogels}

A $0.1 \mathrm{~g}$ sample of APMP aerogel was soaked in RB solution $\left(5 \mathrm{~mL}, 5 \mathrm{~g} \mathrm{~L}^{-1}\right)$ until saturation sorption at ambient temperature $\left(25^{\circ} \mathrm{C}\right)$. The sample was immediately transferred to a vacuum drying oven for $6 \mathrm{~h}$ to remove water at a temperature of $40^{\circ} \mathrm{C}$, which is much lower than the melting point of $\mathrm{RB}\left(210-211^{\circ} \mathrm{C}\right)$ and leaves the molecules on the aerogel structure. 
The absorption capacity of aerogels for RB was calculated as follows: $q_{e}=\left(C_{0} V_{0}-C_{1} V_{1}\right) / m$, where $\mathrm{q}_{\mathrm{e}}\left(\mathrm{mg} \mathrm{g}^{-1}\right)$ is the absorption capacity for dye at equilibrium; $\mathrm{m}(\mathrm{g})$ is the weight of the adsorbent used; $C_{0}$ and $C_{1}\left(\mathrm{mg} \mathrm{L}^{-1}\right)$ are the initial and residual concentrations, respectively; $V_{0}$ and $V_{1}(L)$ are the initial and residual volumes of the dye solution, respectively, because the aerogels not only absorbed the RB but also absorbed moisture.

\subsection{Preparation of N-Doped Carbon Aerogels}

The RB-saturated aerogels were carbonized into a tubular furnace (using Ar atmosphere as a protective gas to provide an oxygen-free environment), which was heated to $500{ }^{\circ} \mathrm{C}\left(2{ }^{\circ} \mathrm{C} \mathrm{min}-1\right)$, kept at $500{ }^{\circ} \mathrm{C}(1 \mathrm{~h})$ to removed impurities, then heated to $900{ }^{\circ} \mathrm{C}$ at a rate of $5{ }^{\circ} \mathrm{C} \mathrm{min}-1$ to prevent structure damage due to the rapid heating rate and kept for $2 \mathrm{~h}$ to ensure complete carbonization before cooling to room temperature naturally.

\subsection{Electrochemical Measurements}

Electrochemical measurements were performed using an electrochemical analyzer (Ivium 1470E, England) with a conventional three-electrode system. The electrode was prepared from a carbon aerogel $(80 \%)$, polytetrafluoroethylene (PTFE) binder $(10 \%)$, and acetylene black $(10 \%)$ in ethanol, coated onto a $1 \times 1 \mathrm{~cm}^{2}$ nickel foam and dried at $120^{\circ} \mathrm{C}(12 \mathrm{~h})$. In a $6 \mathrm{M} \mathrm{KOH}$ electrolyte, modified nickel foam, a $\mathrm{Hg} / \mathrm{HgO}$ electrode, and platinum gauze were used as the working, reference, and counter electrodes, respectively. The cyclic voltammetry $(\mathrm{CV})$ curves were tested in a potential range of -1.0 to $0 \mathrm{~V}$ (5 to $400 \mathrm{mV} \mathrm{s}^{-1}$ ). Galvanostatic charge/discharge (GCD) analysis was obtained in a potential window of -1.0 to $0 \mathrm{~V}\left(1\right.$ to $\left.10 \mathrm{~A} \mathrm{~g}^{-1}\right)$. The electrochemical impedance spectroscopy (EIS) measurements were conducted in the frequency range of $0.01 \mathrm{~Hz}-100 \mathrm{kHz}$. The specific capacitance (C) was calculated as follows:

$$
\begin{aligned}
\mathrm{C}_{\mathrm{GCD}} & =(\mathrm{I} \times \Delta \mathrm{t}) /(\mathrm{m} \times \Delta \mathrm{V}) \\
\mathrm{C}_{\mathrm{CV}} & =\frac{\int I \mathrm{du}}{2 v(2 m \Delta \mathrm{V})} \times 4,
\end{aligned}
$$

where $\mathrm{C}\left(\mathrm{F} \mathrm{g}^{-1}\right)$ is the specific capacitance calculated from the GCD and CV tests; $\mathrm{I}$ is the current load (A); $\Delta \mathrm{t}(\mathrm{s})$ is the discharge time; $\Delta \mathrm{V}(\mathrm{V})$ is the potential window; $\mathrm{m}(\mathrm{mg})$ is the mass of the active materials; $v$ is the scan rate $\left(\mathrm{mV} \mathrm{s}^{-1}\right)$.

\subsection{Characterization}

Scanning electron microscopy (SEM; Quanta 200, FEI, The Netherlands), X-ray photoelectron spectroscopy (PHI5700, Chanhassen, MN, USA), X-ray diffraction (XRD, D/max 2200, Rigaku, Tokyo, Japan), and a Renishaw spectrometer (System 2000, Los Angeles, CA, USA) were used to examine and analyze the morphology, elemental composition, nature of phases, and Raman scattering spectra of the prepared samples.

\section{Results}

\subsection{RB Sorption Capacity of APMP Aerogels}

As shown in Figure 1, the APMP aerogels were effective for RB waste dye adsorption owing to their porosity and wettability [24]. The RB dye containing water was absorbed within a few seconds when in contact with a piece of aerogel at ambient temperature. Our RB absorption testing showed that $0.1 \mathrm{~g}$ of the APMP fiber aerogels could absorb $5 \mathrm{~mL}$ of high concentration RB waste $\left(5 \mathrm{~g} \mathrm{~L}^{-1}\right)$, which reflects the excellent absorption of RB waste $\left(250 \mathrm{mg} \mathrm{g}^{-1}\right)$. As shown in Table 1 , the dye adsorption capacity is higher than many materials such as $\mathrm{MoS}_{2}$, jute stick powder, and kaolinite; however, it is lower than that of some types of activated carbon. Nevertheless, the adsorption rate of our aerogel is 
particularly fast, which indicates that APMP fiber aerogels are an excellent candidate for dealing with RB waste pollution.

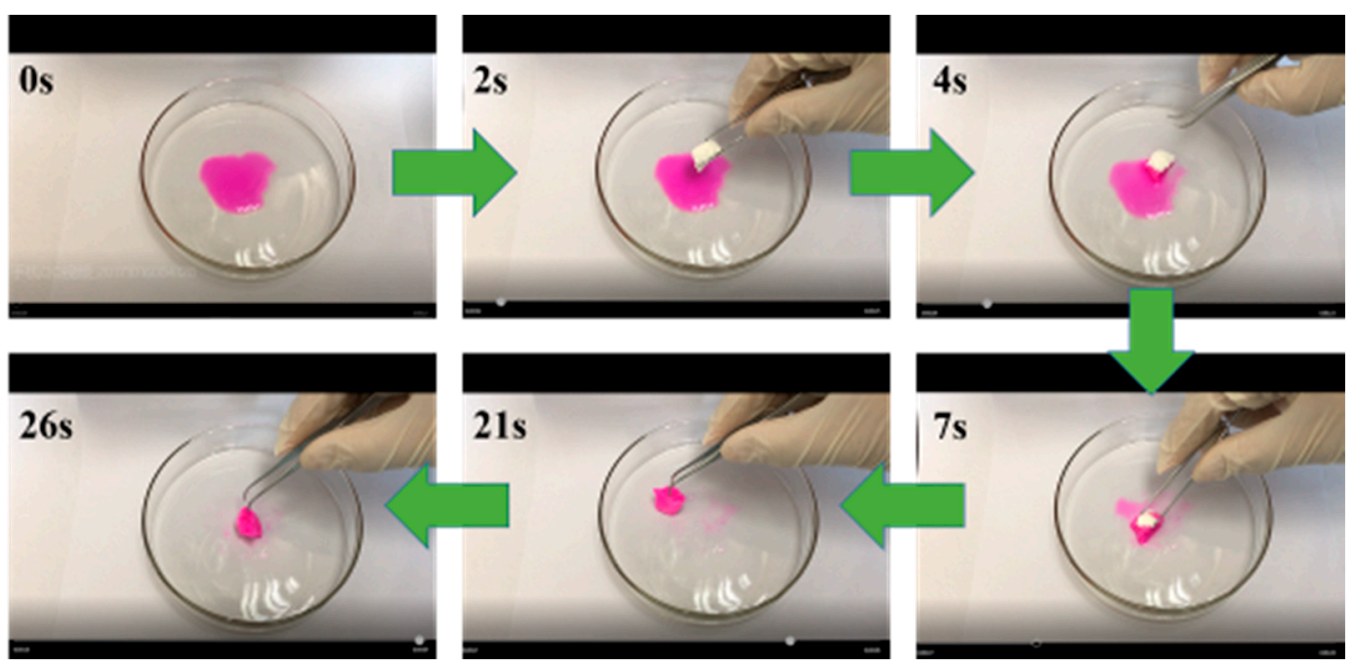

Figure 1. Adsorption process of rhodamine B (RB) waste dye by alkaline peroxide mechanical pulp (APMP) fiber aerogels within $30 \mathrm{~s}$.

Table 1. Comparison of the adsorption capacities of various adsorbents for RB.

\begin{tabular}{|c|c|c|c|}
\hline Adsorbents & $\begin{array}{l}\text { Adsorption Capacity } \\
\left(\mathrm{mg} \mathrm{g}^{-1}\right)\end{array}$ & $\begin{array}{l}\text { Saturation Time } \\
\text { (min) }\end{array}$ & Ref. \\
\hline Activated carbon from scrap tires & 280.1 & 300 & [43] \\
\hline $\begin{array}{l}\text { Activated carbon from lignocellulosic } \\
\text { waste }\end{array}$ & 39.2 & & [44] \\
\hline $\begin{array}{l}\text { Activated carbon from agricultural } \\
\text { by-products }\end{array}$ & 263.8 & 240 & [45] \\
\hline $\mathrm{MoS}_{2}$ & 49.2 & 35 & [46] \\
\hline Iron-pillared bentonite & 98.62 & 40 & [47] \\
\hline $\mathrm{WO}_{3}$ & 64 & & [48] \\
\hline $\mathrm{SnS}_{2} / \mathrm{rGO}$ & 94.07 & 480 & [49] \\
\hline $\mathrm{Fe}_{3} \mathrm{O}_{4} / \mathrm{HA}$ & 161.8 & 15 & [50] \\
\hline Rice husk-based activated carbon & 234 & 120 & [51] \\
\hline Jute stick powder & 87.7 & 60 & [52] \\
\hline $\begin{array}{l}\mathrm{Gg}-\mathrm{cl}-\mathrm{P}(\mathrm{AA}-\mathrm{co}-\mathrm{AAm}) / \mathrm{Fe}_{3} \mathrm{O}_{4} \\
\text { nanocomposite }\end{array}$ & 529.1 & 50 & [53] \\
\hline $\mathrm{GO} /$ silicalite $^{-1}$ & 56.55 & 60 & [54] \\
\hline $\mathrm{SnS}_{2}$ & 200 & 65 & [55] \\
\hline $\mathrm{W}_{18} \mathrm{O}_{49}$ & 120 & & [56] \\
\hline Sodium montmorillonite & 38.27 & 320 & [57] \\
\hline Activated carbon from Lythrum salicaria & 384.62 & 480 & [58] \\
\hline Kaolinite & 46.08 & 80 & [59] \\
\hline APMP fiber aerogels & 250 & 0.5 & $\begin{array}{l}\text { This } \\
\text { work }\end{array}$ \\
\hline
\end{tabular}

\subsection{SEM Observations and Porous Analysis}

The morphologies of the APMP, carbon, and N-doped carbon aerogels were performed by SEM. As displayed in Figure 2a, most of the irregular fibers of the APMP aerogel were intertwined to form a porous structure with many irregular pores ranging from approximately dozens of nanometers to several micrometers. After carbonization, the carbon aerogel showed a network structure with more irregular pores (Figure $2 \mathrm{~b}$ ). The $\mathrm{N}$-doped carbon aerogel also exhibited network structure, and its irregular pores were well preserved (Figure 2c); however, the pore structure showed a slight collapse and stacking of fibers onto each other because the fibers became soft when the APMP fiber aerogel 
absorbed RB dye, resulting in some structural collapse after drying. The result can be further explained by nitrogen absorption test (Figure 2d,e). The specific surface area and total pore volume of the carbon aerogel were $52 \mathrm{~m}^{2} \mathrm{~g}^{-1}$ and $0.04 \mathrm{~cm}^{3} \mathrm{~g}^{-1}$, respectively, which is higher than the N-doped carbon aerogel $\left(30 \mathrm{~m}^{2} \mathrm{~g}^{-1}\right.$ and $0.02 \mathrm{~cm}^{3} \mathrm{~g}^{-1}$, respectively).
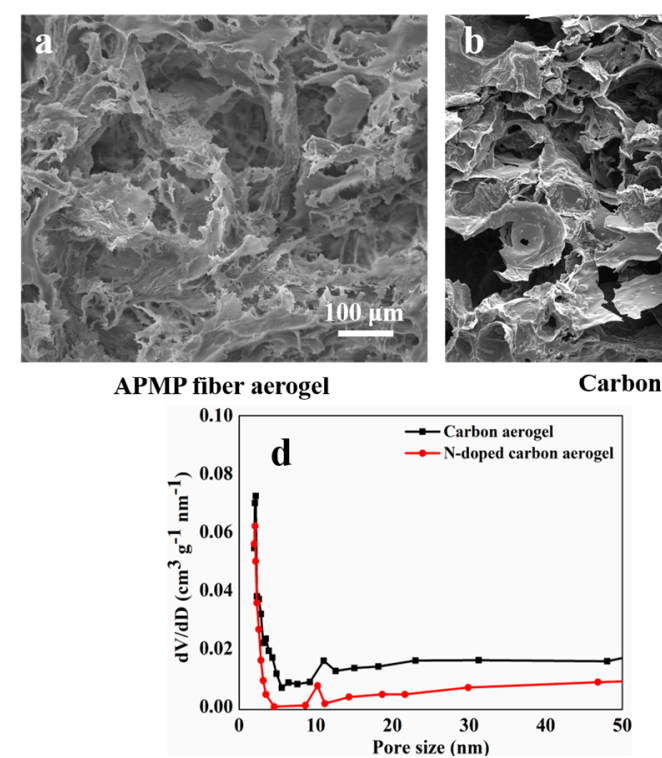

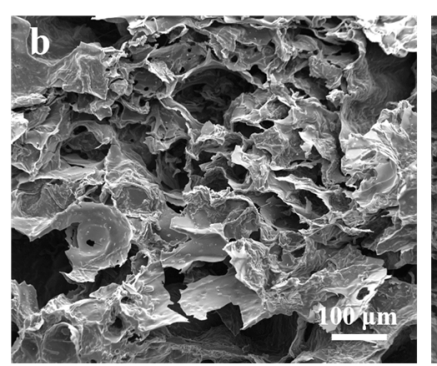

Carbon aerogel

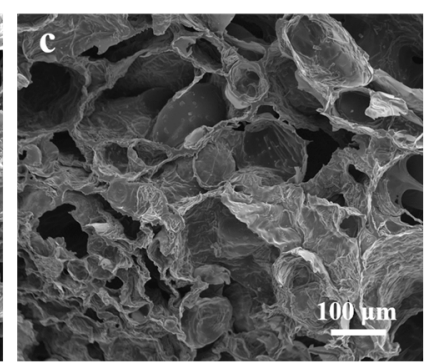

N-doped carbon aerogel

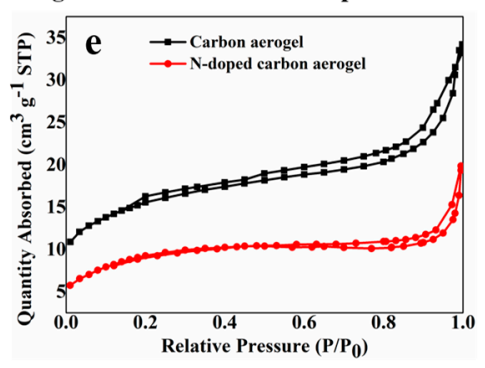

Figure 2. SEM images of (a) APMP aerogel; (b) carbon aerogel; and (c) N-doped carbon aerogel; (d) $\mathrm{N}_{2}$ adsorption-desorption isotherms; and (e) pore size distributions of carbon aerogel and N-doped carbon aerogel.

\subsection{X-ray Photoelectron Spectroscopy (XPS) Analysis}

The chemical structures of RB contain heteroatom $\mathrm{N}$ compounds, making them excellent precursors for preparing doped heteroatom carbon aerogels. To demonstrate that the heteroatom $\mathrm{N}$ was bound to the structure and not combusted during high-temperature carbonation, we confirmed the compositions of the carbon and $\mathrm{N}$-doped carbon aerogels by XPS analysis. The $\mathrm{C} 1 \mathrm{~s}$ peak $(284.3 \mathrm{eV})$ and $\mathrm{O} 1 \mathrm{~s}$ peak $(532.2 \mathrm{eV})$ were clearly visible in the spectra (Figure $3 \mathrm{a})$. The atomic percentage of $\mathrm{C}$ was 86.82 at.\% and that of $\mathrm{O}$ was 13.18 at.\%. The $\mathrm{N}$-doped carbon aerogel showed three peaks assignable to $\mathrm{C} 1 \mathrm{~s}(284.4 \mathrm{eV}), \mathrm{N}$ 1s $(400.7 \mathrm{eV})$, and $\mathrm{O} 1 \mathrm{~s}(532.2 \mathrm{eV})$. The atomic percentages of $\mathrm{C}, \mathrm{N}$, and $\mathrm{O}$ in the $\mathrm{N}$-doped carbon aerogel were 86.92 at.\%, 2.15 at.\%, and 10.93 at.\%, respectively. Thus, $\mathrm{N}$ was successfully doped into the carbon aerogel skeleton. Furthermore, as shown in the fitted $\mathrm{N}$ 1s spectra of the N-doped carbon aerogel (Figure 3b), the N 1s spectrum was fitted by three peaks, namely pyridinic $\mathrm{N}(398 \pm 0.2 \mathrm{eV})$, graphitic $\mathrm{N}(401.2 \pm 0.2 \mathrm{eV})$, and pyrrolic $\mathrm{N}(400.5 \pm 0.2 \mathrm{eV})$, while pyridinic $\mathrm{N}$ and pyrrolic $\mathrm{N}$ were considered as the main contributors to the pseudocapacitance, based on the Faraday reaction and according to previous reports [52]. For example, pyridinic $\mathrm{N}$ and pyrrolic $\mathrm{N}$ could produce pseudocapacitive effects in $\mathrm{KOH}$ aqueous electrolyte, associated with the proton-involved redox processes, as shown in Figure 3c. Thus, the porous N-doped carbon aerogels are expected to have good electrochemical properties. Furthermore, doping heteroatom nitrogen is a promising strategy to further tailor the chemical properties of $\mathrm{sp}^{2}$ carbon materials, which can efficiently improve the wettability of the interface between the electrodes and electrolytes, resulting in a considerable increase in the accessible surface area of the electrolyte. In addition, the presence of $\mathrm{N}$ can also promote electron transfer reactions and consequently enhance the whole capacitive performance of the supercapacitors [53]. 


\section{a}
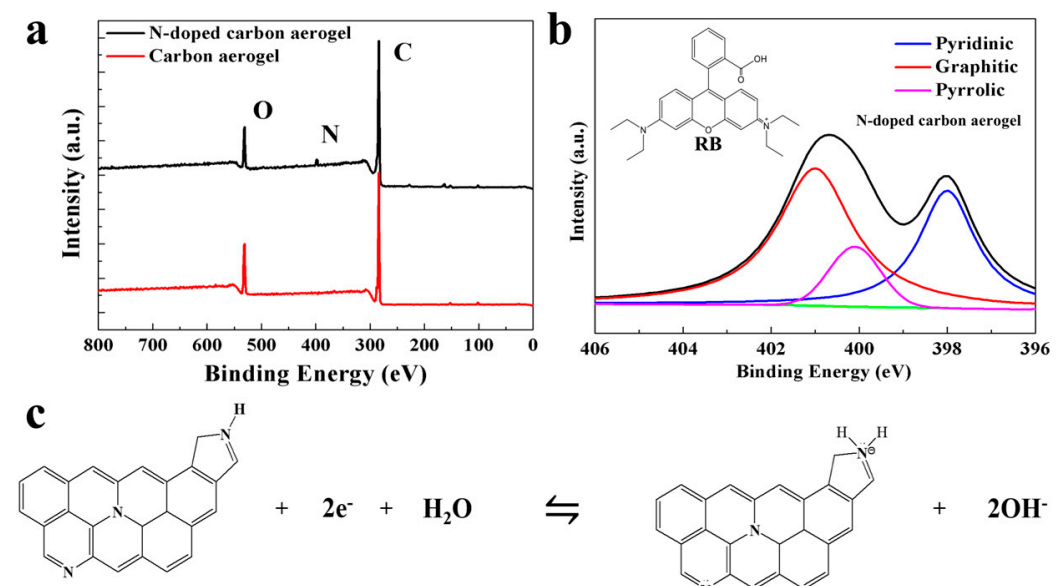

Figure 3. (a) X-ray photoelectron spectroscopy (XPS) spectra of carbon aerogel and N-doped carbon aerogel; (b) high-resolution XPS spectra of the fitted N 1s of N-doped carbon aerogel; (c) the reaction mechanism of the pseudocapacitance effect of pyridine $\mathrm{N}$ and pyrrolic $\mathrm{N}$ in $\mathrm{KOH}$ aqueous electrolyte.

\subsection{XRD and Raman Analysis}

XRD curves of the prepared samples are displayed in Figure 4a. The diffractograms of the materials showed two broad peaks at approximately $22.6^{\circ}(002)$ and $43.6^{\circ}(100)$. The peaks at $22.6^{\circ}$ and $43.6^{\circ}$ correspond to an amorphous carbon portion and graphitic carbon, respectively. We observed a decrease in the intensity of the peaks related to the N-doped carbon aerogel, which might correspond to the entry of heteroatoms into the graphite carbon lattice. We investigated the graphitic structures of the carbon aerogel and N-doped carbon aerogel by Raman spectroscopy. In their Raman spectra, both exhibited two peaks at $1337.5 \mathrm{~cm}^{-1}$ ( $\mathrm{D}$ band) and $1594.5 \mathrm{~cm}^{-1}$ ( $\mathrm{G}$ band). The $\mathrm{D}$ band is related to structural defects of disordered carbon, whereas the $\mathrm{G}$ band is associated with the ordered carbon vibration $[3,48]$. The ratio of $\mathrm{I}_{\mathrm{D}} / \mathrm{I}_{\mathrm{G}}$ could appraise the graphitic structure of synthesized materials, and the calculated values were 0.94 and 0.98 for the carbon aerogel and N-doped carbon aerogel, respectively, indicating a high degree of graphitization in both samples, in agreement with the XRD results. Graphitization of carbon materials increases their electric conductivity and decreases the equivalent series resistance of supercapacitors; thus, these features will likely affect the impedance behavior [53].
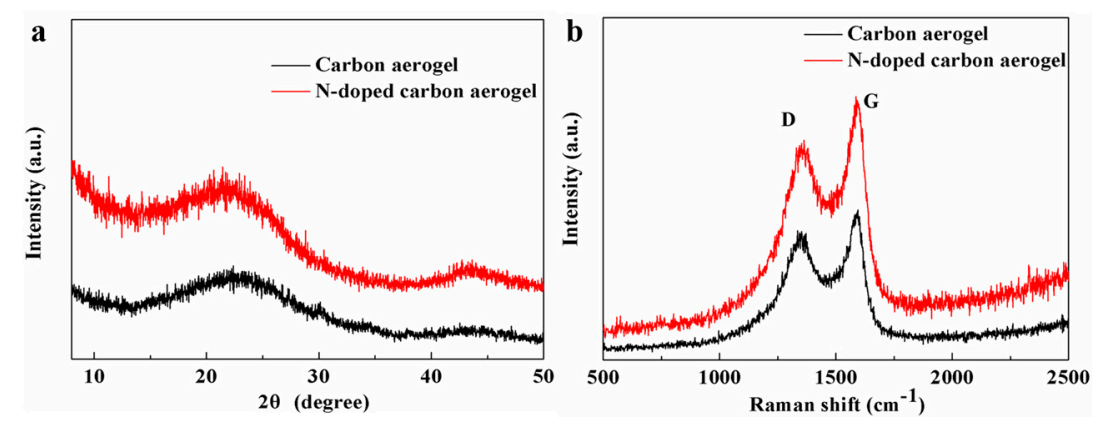

Figure 4. (a) XRD and (b) Raman analysis of carbon aerogel and N-doped carbon aerogel.

\subsection{Electrochemical Performance}

The electrochemical properties of the carbon aerogel and N-doped carbon aerogel were tested in a $6 \mathrm{M} \mathrm{KOH}$ aqueous electrolyte at room temperature. Figure 5 a compares the $\mathrm{CV}$ curves of the carbon aerogel and $\mathrm{N}$-doped carbon aerogel $\left(10 \mathrm{mV} \mathrm{s}^{-1}\right)$. Both samples exhibited approximately rectangular curves, suggesting that the supercapacitors possessed a super capacitive behavior and good reversibility. In addition, $\mathrm{N}$-doped carbon aerogel electrodes showed higher current densities than 
those of the carbon aerogel sample, indicating that the N-doped carbon aerogel had high capacitances. The result can be further explained by $\mathrm{C}_{\mathrm{CV}}$ values at $10 \mathrm{mV} \mathrm{s}^{-1}$. The $\mathrm{C}_{\mathrm{CV}}$ for the $\mathrm{N}$-doped carbon aerogel and carbon aerogel were $120 \mathrm{~F} \mathrm{~g}^{-1}$ and $104 \mathrm{~F} \mathrm{~g}^{-1}$, respectively. Figure $5 \mathrm{~b}$ shows the $\mathrm{CV}$ curves of the $\mathrm{N}$-doped carbon aerogel aqueous electrolyte capacitors at scan rates from 5 to $400 \mathrm{mV}$ $\mathrm{s}^{-1}$. The current response increased as the scan rate increased, and the shapes of the $\mathrm{CV}$ curves were retained, indicating that $\mathrm{N}$-doped carbon aerogel exhibited an ideal electrical double layer. Hence, the electrodes exhibited supercapacitor electrode behavior and a good rate capability. Comparing the carbon aerogel and $\mathrm{N}$-doped carbon aerogel, it can be observed that the specific surface area and total pore volume decrease a little but that the electrochemical performance capacitance increases. Therefore, doping heteroatom nitrogen is a promising strategy to further tailor the chemical properties of $\mathrm{sp}^{2}$ carbon materials and can efficiently improve the wettability of the interface between electrodes and electrolytes, resulting in a considerable increase in the accessible surface area of the electrolyte, promoting electron transfer reactions and consequently enhancing the whole capacitive performance of the supercapacitors. Thus, we attribute the high capacitive performance of our $\mathrm{N}$-doped carbon aerogel electrodes to the 3D network structure with $\mathrm{N}$-doping.

The galvanostatic charge/discharge performances of the prepared sample electrodes at $1 \mathrm{~A} \mathrm{~g}^{-1}$ were tested (Figure $5 \mathrm{c}$ ). The $\mathrm{N}$-doped carbon aerogels had a better capacitance performance owing to their greater charge/discharge time and more symmetrical curves. We attribute these features to the porous structure of nitrogen-doped aerogels, resulting in the kinetics of ion and electron transport being increased at the electrode/electrolyte interface. As shown in Figure $5 \mathrm{~d}$, the galvanostatic charge/discharge performance of the $\mathrm{N}$-doped carbon aerogel electrode ( 1 to $10 \mathrm{~A} \mathrm{~g}^{-1}$ ) was also tested. Obviously, as the current density increased, the charge/discharge time decreased. This can be attributed to the shorter time for electrolyte ions to diffuse into the pores of the electrodes. Furthermore, at different current densities, the charge/discharge curves of the N-doped carbon aerogel also exhibited an equicrural triangle shape, suggesting ideal capacitor behavior (Figure 5 c).

Figure 5e exhibits the specific capacitances of the carbon aerogel and $\mathrm{N}$-doped carbon aerogel calculated from the galvanostatic discharge data. At the same current density from 1 to $10 \mathrm{~A} \mathrm{~g}^{-1}$, the N-doped carbon aerogel showed a higher specific capacitance. For example, the N-doped carbon aerogel possessed a specific capacitance of $185.8 \mathrm{~F} \mathrm{~g}^{-1}$ at $1 \mathrm{~A} \mathrm{~g}^{-1}$, which was higher than the values for the carbon aerogel (155 $\mathrm{F} \mathrm{g}^{-1}$ at $\left.1 \mathrm{~A} \mathrm{~g}^{-1}\right)$, and the specific capacitance of the N-doped carbon aerogel at $10 \mathrm{~A} \mathrm{~g} \mathrm{~g}^{-1}$ remained $105 \mathrm{~F} \mathrm{~g}^{-1}$, while the carbon aerogel only showed capacities of $84 \mathrm{~F} \mathrm{~g}^{-1}$, suggesting the beneficial effects of the $\mathrm{N}$ heteroatoms doped into the carbon aerogels. Moreover, a specific capacitance of $105 \mathrm{~F} \mathrm{~g}^{-1}$ was maintained for the $\mathrm{N}$-doped carbon aerogel at $10 \mathrm{~A} \mathrm{~g}^{-1}$, which demonstrates good performance stability. Furthermore, the specific capacitance of the N-doped carbon aerogel was higher than other $\mathrm{N}$-doped carbon materials, such as heteroatom-doped carbon nanofiber aerogels (171.2 $\mathrm{F} \mathrm{g}^{-1}, 0.5 \mathrm{~A} \mathrm{~g}^{-1}$ ) [60], sulfur and nitrogen dual-doping carbon materials (170 $\mathrm{F} \mathrm{g}^{-1}$, $1 \mathrm{~A} \mathrm{~g}^{-1}$ ) [61], and $\mathrm{KOH}$-activated carbon aerogels (152.6 F g${ }^{-1}, 0.5 \mathrm{~A} \mathrm{~g}^{-1}$ ) [62].

Figure $5 \mathrm{f}$ shows the electrochemical impedance analysis of the carbon aerogel and $\mathrm{N}$-doped carbon aerogel at an open circuit potential $(0.01 \mathrm{~Hz}$ to $100 \mathrm{kHz})$. The low-frequency region of the Nyquist spectrum of the $\mathrm{N}$-doped carbon aerogel was much closer to vertical lines, which confirms the dominance of the electric double-layer capacitor as well as the good capacitive performance. In addition, the length of the Warburg-type lines (the $45^{\circ}$ segment) was short, which indicates low resistance and high ion diffusion efficiency for ion transport. At high frequency, the appearance of the semicircle indicates that the $\mathrm{N}$-doped carbon aerogel has a very low charge transfer resistance and ion diffusion resistance. The equivalent series resistance obtained from the first intersection with the real axis is only $0.5 \Omega$, further confirming a high charge transfer rate between the electrolyte and active materials. 

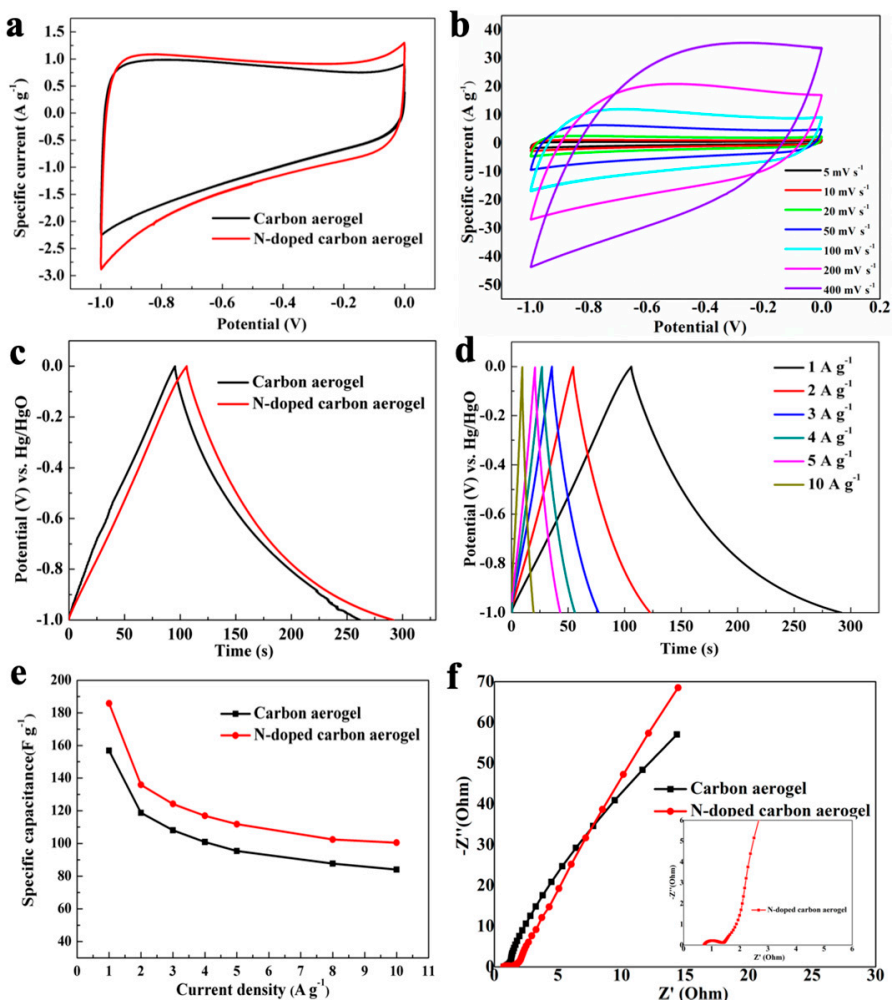

Figure 5. Electrochemical capacitive behaviors of the carbon aerogel and N-doped carbon aerogel. (a) CV curves at a scan of $10 \mathrm{mV} \mathrm{s}^{-1}(6 \mathrm{M} \mathrm{KOH}) ;(\mathbf{b}) \mathrm{CV}$ curves of the N-doped carbon aerogel at different scan rates; (c) galvanostatic charge/discharge curves of the carbon aerogel and N-doped carbon aerogel at $1 \mathrm{~A} \mathrm{~g}^{-1}$; (d) galvanostatic charge/discharge curves of the N-doped carbon aerogel with different current densities; (e) specific capacitances of the carbon aerogel and N-doped carbon aerogel at different current densities; (f) Nyquist plots of the carbon aerogel and N-doped carbon aerogel.

\section{Conclusions}

We have successfully reported an efficient and simple strategy for preparing $\mathrm{N}$-doped carbon aerogels by the carbonization of APMP aerogels saturated with rhodamine dye. The APMP fiber aerogel exhibited a high adsorption capacity and $0.1 \mathrm{~g}$ of aerogel could easily absorb $5 \mathrm{~mL}$ of highly concentrated RB waste $\left(5 \mathrm{~g} \mathrm{~L}^{-1}\right)$ within $30 \mathrm{~s}$. In addition, $\mathrm{N}$ heteroatoms were successfully doped into the 3D network structure after carbonization, and the specific capacitance of N-doped carbon aerogel reached $185 \mathrm{~F} \mathrm{~g}^{-1}$ ( $1 \mathrm{~A} \mathrm{~g}^{-1}$ current density). This method not only addresses the problem of dye wastewater but also turns the waste into useful materials, providing an environmentally friendly and low-cost strategy for fabricating N-doped carbon aerogels. Other organic dyes such as methyl orange, methylene blue, or crystal violet could be also be used to prepared $\mathrm{N}$-doped carbon materials in the same way.

Author Contributions: Conceptualization, S.L.; data curation, L.E, J.S., and Z.W.; funding acquisition, W.L.; resources, S.L.; writing of original draft, L.E.

Funding: This work was supported by the National Key R\&D Program of China (2017YFD0601006), the National Natural Science Foundation of China (No. 31890773, 31570567), and the Fundamental Research Funds for the Central Universities (2572017ET02, 2572017AB15).

Conflicts of Interest: The authors declare no conflict of interest.

\section{References}

1. Sevilla, M.; Mokaya, R. Energy storage applications of activated carbons: Supercapacitors and hydrogen storage. Energy Environ. Sci. 2014, 7, 1250-1280. [CrossRef] 
2. Li, K.; Liu, X.; Chen, S.; Pan, W.; Zhang, J. A flexible solid-state supercapacitor based on graphene/polyaniline paper electrodes. J. Energy Chem. 2018. [CrossRef]

3. Li, Y.; Han, X.; Yi, T.; He, Y.; Li, X. Review and prospect of $\mathrm{NiCo}_{2} \mathrm{O}_{4}$-based composite materials for supercapacitor electrodes. J. Energy Chem. 2018. [CrossRef]

4. Hao, L.; Li, X.; Zhi, L. Carbonaceous electrode materials for supercapacitors. Adv. Mater. 2013, 25, 3899-3904. [CrossRef] [PubMed]

5. Wang, G.; Zhang, L.; Zhang, J. A review of electrode materials for electrochemical supercapacitors. Chem. Soc. Rev. 2012, 41, 797-828. [CrossRef]

6. Yang, I.; Kwon, D.; Kim, M.-S.; Jung, J.C. A comparative study of activated carbon aerogel and commercial activated carbons as electrode materials for organic electric double-layer capacitors. Carbon 2018, 132, 503-511. [CrossRef]

7. Wei, X.; Jiang, X.; Wei, J.; Gao, S. Functional groups and pore size distribution do matter to hierarchically porous carbons as high-rate-performance supercapacitors. Chem. Mater. 2016, 28, 445-458. [CrossRef]

8. Liu, N.; Shen, J.; Liu, D. Activated high specific surface area carbon aerogels for EDLCs. Microporous Mesoporous Mater. 2013, 167, 176-181. [CrossRef]

9. Lei, E.; Li, W.; Ma, C.; Xu, Z.; Liu, S. $\mathrm{CO}_{2}$-activated porous self-templated N-doped carbon aerogel derived from banana for high-performance supercapacitors. Appl. Surf. Sci. 2018, 457, 477-486.

10. Sinan, N.; Unur, E. Hydrothermal conversion of lignocellulosic biomass into high-value energy storage materials. J. Energy Chem. 2017, 26, 783-789. [CrossRef]

11. Song, L.-T.; Wu, Z.-Y.; Liang, H.-W.; Zhou, F.; Yu, Z.-Y.; Xu, L.; Pan, Z.; Yu, S.-H. Macroscopic-scale synthesis of nitrogen-doped carbon nanofiber aerogels by template-directed hydrothermal carbonization of nitrogen-containing carbohydrates. Nano Energy 2016, 19, 117-127. [CrossRef]

12. Chen, S.; Bi, J.; Zhao, Y.; Yang, L.; Zhang, C.; Ma, Y.; Wu, Q.; Wang, X.; Hu, Z. Nitrogen-doped carbon nanocages as efficient metal-free electrocatalysts for oxygen reduction reaction. Adv. Mater. 2012, 24, 5593-5597. [CrossRef] [PubMed]

13. Chen, C.; Yu, D.; Zhao, G.; Du, B.; Tang, W.; Sun, L.; Sun, Y.; Besenbacher, F.; Yu, M. Three-dimensional scaffolding framework of porous carbon nanosheets derived from plant wastes for high-performance supercapacitors. Nano Energy 2016, 27, 377-389. [CrossRef]

14. Long, C.; Jiang, L.; Wu, X.; Jiang, Y.; Yang, D.; Wang, C.; Wei, T.; Fan, Z. Facile synthesis of functionalized porous carbon with three-dimensional interconnected pore structure for high volumetric performance supercapacitors. Carbon 2015, 93, 412-420. [CrossRef]

15. Su, F.; Poh, C.K.; Chen, J.S.; Xu, G.; Wang, D.; Li, Q.; Lin, J.; Lou, X.W. Nitrogen-containing microporous carbon nanospheres with improved capacitive properties. Energy Environ. Sci. 2011, 4, 717-724. [CrossRef]

16. Yang, M.; Cheng, B.; Song, H.; Chen, X. Preparation and electrochemical performance of polyaniline-based carbon nanotubes as electrode material for supercapacitor. Electrochim. Acta 2010, 55, 7021-7027. [CrossRef]

17. Zhang, J.; Xu, D.; Qian, W.; Zhu, J.; Yan, F. Host-guest inclusion complexes derived heteroatom-doped porous carbon materials. Carbon 2016, 105, 183-190. [CrossRef]

18. Ensafi, A.A.; Alinajafi, H.A.; Rezaei, B. Thermally reduced graphene oxide/polymelamine formaldehyde nanocomposite as a high specific capacitance electrochemical supercapacitor electrode. J. Mater. Chem. A 2018, 6, 6045-6053. [CrossRef]

19. Cazetta, A.L.; Martins, A.C.; Pezoti, O.; Bedin, K.C.; Beltrame, K.K.; Asefa, T.; Almeida, V.C. Synthesis and application of N-S-doped mesoporous carbon obtained from nanocasting method using bone char as heteroatom precursor and template. Chem. Eng. J. 2016, 300, 54-63. [CrossRef]

20. Wang, X.; Li, X.; Zhang, L.; Yoon, Y.; Weber, P.K.; Wang, H.; Guo, J.; Dai, H. N-doping of graphene through electrothermal reactions with ammonia. Science 2009, 324, 768-771. [CrossRef]

21. Maleki, H. Recent advances in aerogels for environmental remediation applications: A review. Chem. Eng. J. 2016, 300, 98-118. [CrossRef]

22. Pierre, A.C.; Pajonk, G.M. Chemistry of aerogels and their applications. Chem. Rev. 2002, 102, 4243-4264. [CrossRef] [PubMed]

23. Huang, J.; Liu, H.; Chen, S.; Ding, C. Graphene aerogel prepared through double hydrothermal reduction as high-performance oil adsorbent. Adv. Mater. Sci. Eng. B 2017, 226, 141-150. [CrossRef]

24. Yang, X.; Shi, K.; Zhitomirsky, I.; Cranston, E.D. Cellulose nanocrystal aerogels as universal 3D lightweight substrates for supercapacitor materials. Adv. Mater. 2015, 27, 6104-6109. [CrossRef] [PubMed] 
25. Zhang, Y.; Zhu, J.; Ren, H.; Bi, Y.; Zhang, L. Facile Synthesis of Nitrogen-Doped Graphene Aerogels for Electrode Materials in Supercapacitors. Chin. J. Chem. 2017, 35, 1069-1078. [CrossRef]

26. Bi, H.; Yin, Z.; Cao, X.; Xie, X.; Tan, C.; Huang, X.; Chen, B.; Chen, F.; Yang, Q.; Bu, X.; et al. Carbon fiber aerogel made from raw cotton: A novel, efficient and recyclable sorbent for oils and organic solvents. Adv. Mater. 2013, 25, 5916-5921. [CrossRef]

27. Zhang, Y.; Zuo, L.; Zhang, L.; Huang, Y.; Lu, H.; Fan, W.; Liu, T. Cotton wool derived carbon fiber aerogel supported few-layered $\mathrm{MoSe}_{2}$ nanosheets as efficient electrocatalysts for hydrogen evolution. ACS Appl. Mater. Interfaces 2016, 8, 7077-7085. [CrossRef]

28. Du, J.; Liu, L.; Hu, Z.; Yu, Y.; Zhang, Y.; Hou, S.; Chen, A. Raw-cotton-derived N-doped carbon fiber aerogel as an efficient electrode for electrochemical capacitors. ACS Sustain. Chem. Eng. 2018, 6, 4008-4015. [CrossRef]

29. Hao, P.; Zhao, Z.; Tian, J.; Li, H.; Sang, Y.; Yu, G.; Cai, H.; Liu, H.; Wong, C.P.; Umar, A. Hierarchical porous carbon aerogel derived from bagasse for high performance supercapacitor electrode. Nanoscale 2014, 6, 12120-12129. [CrossRef]

30. Yang, S.; Chen, L.; Mu, L.; Hao, B.; Ma, P.-C. Low cost carbon fiber aerogel derived from bamboo for the adsorption of oils and organic solvents with excellent performances. RSC Adv. 2015, 5, 38470-38478. [CrossRef]

31. Wu, Z.Y.; Liang, H.W.; Chen, L.F.; Hu, B.C.; Yu, S.H. Bacterial cellulose: A robust platform for design of three dimensional carbon-based functional nanomaterials. Acc. Chem. Res. 2016, 49, 96-105. [CrossRef] [PubMed]

32. Feng, J.; Nguyen, S.T.; Fan, Z.; Duong, H.M. Advanced fabrication and oil absorption properties of super-hydrophobic recycled cellulose aerogels. Chem. Eng. J. 2015, 270, 168-175. [CrossRef]

33. Li, L.; Hu, T.; Sun, H.; Zhang, J.; Wang, A. Pressure-sensitive and conductive carbon aerogels from poplars catkins for selective oil absorption and oil/water separation. ACS Appl. Mater. Interfaces 2017, 9, 18001-18007. [CrossRef] [PubMed]

34. Maldonado-Hódar, F.J.; Moreno-Castilla, C.; Pérez-Cadenas, A.F. Catalytic combustion of toluene on platinum-containing monolithic carbon aerogels. Appl. Catal. B 2004, 54, 217-224. [CrossRef]

35. Lei, E.; Li, W.; Ma, C.; Liu, S. An ultra-lightweight recyclable carbon aerogel from bleached softwood kraft pulp for efficient oil and organic absorption. Mater. Chem. Phys. 2018, 214, 291-296.

36. Zuo, L.; Zhang, Y.; Zhang, L.; Miao, Y.E.; Fan, W.; Liu, T. Polymer/carbon-based hybrid aerogels: Preparation, properties and applications. Materials 2015, 8, 6806-6848. [CrossRef]

37. Yin, A.; Xu, F.; Zhang, X. Fabrication of biomass-derived carbon aerogels with high adsorption of oils and organic solvents: Effect of hydrothermal and post-pyrolysis processes. Materials 2016, 9, 758. [CrossRef]

38. Wu, X.-L.; Wen, T.; Guo, H.-L.; Yang, S.; Wang, X.; Xu, A.-W. Biomass-Derived Sponge-like Carbonaceous Hydrogels and Aerogels for Supercapacitors. J. Am. Chem. Soc. 2013, 7, 3589-3597. [CrossRef]

39. Katanyoota, P.; Chaisuwan, T.; Wongchaisuwat, A.; Wongkasemjit, S. Novel polybenzoxazine-based carbon aerogel electrode for supercapacitors. Adv. Mater. Sci. Eng. B 2010, 167, 36-42. [CrossRef]

40. Yu, M.; Han, Y.; Li, Y.; Li, J.; Wang, L. Polypyrrole-anchored cattail biomass-derived carbon aerogels for high performance binder-free supercapacitors. Carbohydr. Polym. 2018, 199, 555-562. [CrossRef]

41. Yan, S.C.; Li, Z.S.; Zou, Z.G. Photodegradation of rhodamine B and methyl orange over boron-doped g- $\mathrm{C}_{3} \mathrm{~N}_{4}$ under visible light irradiation. Langmuir 2010, 26, 3894-3901. [CrossRef] [PubMed]

42. Jin, C.; Han, S.; Li, J.; Sun, Q. Fabrication of cellulose-based aerogels from waste newspaper without any pretreatment and their use for absorbents. Carbohydr. Polym. 2015, 123, 150-156. [CrossRef] [PubMed]

43. Li, L.; Liu, S.; Zhu, T. Application of activated carbon derived from scrap tires for adsorption of Rhodamine, B. J. Environ. Sci. 2010, 22, 1273-1280. [CrossRef]

44. Da Silva Lacerda, V.; Lopez-Sotelo, J.B.; Correa-Guimaraes, A.; Hernandez-Navarro, S.; Sanchez-Bascones, M.; Navas-Gracia, L.M.; Martin-Ramos, P.; Martin-Gil, J. Rhodamine B removal with activated carbons obtained from lignocellulosic waste. J. Environ. Manage. 2015, 155, 67-76. [CrossRef] [PubMed]

45. Gad, H.M.; El-Sayed, A.A. Activated carbon from agricultural by-products for the removal of Rhodamine-B from aqueous solution. J. Hazard. Mater. 2009, 168, 1070-1081. [CrossRef] [PubMed]

46. Wang, X.; Ding, J.; Yao, S.; Wu, X.; Feng, Q.; Wang, Z.; Geng, B. High supercapacitor and adsorption behaviors of flower-like $\mathrm{MoS}_{2}$ nanostructures. J. Mater. Chem. A 2014, 2, 15958-15963. [CrossRef]

47. Hou, M.F.; Ma, C.X.; Zhang, W.D.; Tang, X.Y.; Fan, Y.N.; Wan, H.F. Removal of rhodamine B using iron-pillared bentonite. J. Hazard. Mater. 2011, 186, 1118-1123. [CrossRef] 
48. Zhu, J.; Wang, S.; Xie, S.; Li, H. Hexagonal single crystal growth of $\mathrm{WO}_{3}$ nanorods along a [110] axis with enhanced adsorption capacity. Chem. Commun. 2011, 47, 4403-4405. [CrossRef]

49. Bian, X.; Lu, X.; Xue, Y.; Zhang, C.; Kong, L.; Wang, C. A facile one-pot hydrothermal method to produce $\mathrm{SnS} 2 /$ reduced graphene oxide with flake-on-sheet structures and their application in the removal of dyes from aqueous solution. J. Colloid Interface Sci. 2013, 406, 37-43. [CrossRef]

50. Peng, L.; Qin, P.; Lei, M.; Zeng, Q.; Song, H.; Yang, J.; Shao, J.; Liao, B.; Gu, J. Modifying $\mathrm{Fe}_{3} \mathrm{O}_{4}$ nanoparticles with humic acid for removal of Rhodamine B in water. J. Hazard. Mater. 2012, 209, 193-198. [CrossRef]

51. Ding, L.; Zou, B.; Gao, W.; Liu, Q.; Wang, Z.; Guo, Y.; Wang, X.; Liu, Y. Adsorption of Rhodamine-B from aqueous solution using treated rice husk-based activated carbon. Colloids Surf. A 2014, 446, 1-7. [CrossRef]

52. Panda, G.C.; Das, S.K.; Guha, A.K. Jute stick powder as a potential biomass for the removal of congo red and rhodamine B from their aqueous solution. J. Hazard. Mater. 2009, 164, 374-379. [CrossRef] [PubMed]

53. Mittal, H.; Mishra, S.B. Gum ghatti and $\mathrm{Fe}_{3} \mathrm{O}_{4}$ magnetic nanoparticles based nanocomposites for the effective adsorption of rhodamine B. Carbohydr. Polym. 2014, 101, 1255-1264. [CrossRef] [PubMed]

54. Cheng, Z.-L.; Li, Y.-X.; Liu, Z. Fabrication of graphene oxide/silicalite-1 composites with hierarchical porous structure and investigation on their adsorption performance for rhodamine B. J. Ind. Eng. Chem. 2017, 55, 234-243. [CrossRef]

55. Wang, S.; Yang, B.; Liu, Y. Synthesis of a hierarchical SnS2 nanostructure for efficient adsorption of Rhodamine B dye. J. Colloid Interface Sci. 2017, 507, 225-233. [CrossRef] [PubMed]

56. Gao, X.; Xiao, F.; Yang, C.; Wang, J.; Su, X. Hydrothermal fabrication of W18O49 nanowire networks with superior performance for water treatment. J. Mater. Chem. A 2013, 1, 5831. [CrossRef]

57. Selvam, P.P.; Preethi, S.; Basakaralingam, P.; Thinakaran, N.; Sivasamy, A.; Sivanesan, S. Removal of rhodamine B from aqueous solution by adsorption onto sodium montmorillonite. J. Hazard. Mater. 2008, 155, 39-44. [CrossRef] [PubMed]

58. Huang, Y.; Zheng, X.; Feng, S.; Guo, Z.; Liang, S. Enhancement of rhodamine B removal by modifying activated carbon developed from Lythrum salicaria L. with pyruvic acid. Colloids Surf. A 2016, 489, 154-162. [CrossRef]

59. Khan, T.A.; Dahiya, S.; Ali, I. Use of kaolinite as adsorbent: Equilibrium, dynamics and thermodynamic studies on the adsorption of Rhodamine B from aqueous solution. Appl. Clay Sci. 2012, 69, 58-66. [CrossRef]

60. Wu, Z.-Y.; Liang, H.-W.; Li, C.; Hu, B.-C.; Xu, X.-X.; Wang, Q.; Chen, J.-F.; Yu, S.-H. Dyeing bacterial cellulose pellicles for energetic heteroatom doped carbon nanofiber aerogels. Nano Res. 2014, 7, 1861-1872. [CrossRef]

61. Xu, G.; Han, J.; Ding, B.; Nie, P.; Pan, J.; Dou, H.; Li, H.; Zhang, X. Biomass-derived porous carbon materials with sulfur and nitrogen dual-doping for energy storage. Green Chem. 2015, 17, 1668-1774. [CrossRef]

62. Yu, M.; Li, J.; Wang, L. KOH-activated carbon aerogels derived from sodium carboxymethyl cellulose for high-performance supercapacitors and dye adsorption. Chem. Eng. J. 2017, 310, 300-306. [CrossRef] 